\title{
Os fins e os meios navais no âmbito da Zona Econômica Exclusiva
}

\section{The ends and naval means in the context of the Economic Exclusive Zone}

\section{ÉRICO ESTEVES DUARTE GUSTAVO HACK DE MOURA}

\section{INTRODUÇÃO}

O tema do presente trabalho é a relação dos fins e meios navais no âmbito da Zona Econômica Exclusiva (ZEE). Desde 1994, com a entrada em vigor da Convenção das Nações Unidas sobre o Direito do Mar (CNUDM) a relação dos Estados com o ambiente oceânico sofreu uma alteração profunda. Em 1945, o presidente dos Estados Unidos, Harry Truman, fez uma declaração em que reconhecia os recursos do subsolo marítimo em sua plataforma continental como partes da jurisdição desse país. Seguindo os passos iniciais dos Estados Unidos, os países em desenvolvimento começaram a reivindicar territórios além das 12 milhas náuticas habituais, principalmente como zonas de pesca. Na América do Sul, Chile, Equador e Peru, através da Declaração de Santiago, afirmaram sua soberania sobre um território de 200 milhas náuticas - distância extraída da Declaração do Panamá de 1939, a qual estabeleceu zona de neutralidade e segurança ao redor do continente americano. A proposta de criação de ZEEs foi sugerida pelo Quênia, em 1971, ao Comitê Consultivo Afro-Asiático, que, no ano seguinte, oficializou a proposta com a Declaração de Addis Abeba. Apesar da vanguarda dos países em desenvolvimento, é também verdade que no Entreguerras houve tentativas, fracassadas, de codificar o regime de águas territoriais no Segundo Comitê da Conferência de Haia de 1930.

Érico Esteves Duarte - Professor de Estudos Estratégicos e Relações Internacionais da Universidade Federal do Rio Grande do Sul. Doutor e Mestre em Ciências da Engenharia da Produção (área de concentração Estudos Estratégicos) pela Coppe/UFRJ

Gustavo Hack de Moura - Mestre em Estudos Estratégicos Internacionais pela Universidade Federal do Rio Grande do Sul. 
No momento das negociações da III Conferência das Nações Unidas para o Direito do Mar, duas propostas existiam para a territorialização dos oceanos. As potências marítimas, grupo que englobava, entre outros, Estados Unidos e União Soviética e conseguiu impor seu interesse nas negociações, defendiam que, dentro da nova zona, os Estados usuários das linhas de comunicação marítima mantivessem as mesmas liberdades de navegação e que os Estados costeiros não ganhassem soberania. Já os países em desenvolvimento advogavam por um regime em que os Estados costeiros adquirissem soberania e os Estados usuários mantivessem algumas liberdades (Beckman and Davenport 2012, 5-6).

A CNUDM fez surgir, então, um novo regime, considerado sui generis porque não é nem parte do alto-mar, nem território do Estado costeiro, e conta com sua própria moldura legal. (Aguilar 1976, 153). Segundo esse novo regime, o Estado costeiro tem o direito de exploração exclusivo dos recursos, vivos ou não, ali presentes, o que se chamou de direitos soberanos. Em contrapartida, estabelece os deveres de conservação, gestão e utilização sustentável daqueles, através, por exemplo, do estabelecimento de quotas de pesca. Importante, essa gama de responsabilidades e direitos sobre os recursos, instalações e o meio ambiente possibilita que o Estado costeiro tome medidas como embarque, inspeção, apreensão e posterior acusação penal de embarcações infratoras, nacionais ou estrangeiras, na ZEE. Entretanto, conforme o regime, deve-se respeitar usos não econômicos dessa área por navios estrangeiros.

Embora a Convenção tenha apenas formalizado uma mudança que já vinha se estruturando há algum tempo, o fato é que ela definiu novos parâmetros para o uso da força no mar. Consequentemente, os Estados passaram a ter a possibilidade de empregar o poder naval a fim de garantir a continuidade da exploração econômica do local. No entanto, existe uma brecha lógica entre o fim político, a exploração econômica da ZEE, e o uso dos meios navais. Aquela consiste na inexistência de uma relação direta entre a atividade-fim destes, o uso da força no mar, e o novo propósito político emergente com as ZEEs. É preciso um novo instrumento conceitual que permita conectar de forma satisfatória os meios navais à exploração das novas zonas marítimas. Till (2018, cap. 11) consagrou a "boa ordem no mar" como o objetivo da atividade policial dos Estados em sua ZEE. Entretanto, esse objetivo é desprendido de um conceito teórico mais amplo capaz de enquadrar a atividade naval para análise. Uma das consequências disso é a tentativa de aplicação do termo Comando do Mar para as atividades navais relacionadas à gestão da ZEE.

A definição de Comando do Mar mais difundida ainda é aquela expressa por Corbett $(2005,94)$, para quem aquele é "nada além do controle das 
linhas de comunicação, seja para propósitos comerciais seja para propósitos militares" - veja-se Till (2018) para corroboração dessa definição. $\mathrm{Na}$ visão de Corbett, esse controle das linhas de comunicação era relativo, podendo variar no tempo e no espaço em relação ao oponente. Contudo, essa relatividade não impedia a exploração do mar para os fins estratégicos, sendo que não era o Comando do Mar, em si mesmo, que importava, mas a forma como esse Comando servia à guerra sendo travada - em outras palavras, era um meio para um fim (Till 2018, cap. 6). Já Mahan, antes de Corbett, tratou o conceito de forma absoluta, considerando que ou a força naval detém o controle das linhas de comunicação ou o uso estratégico do mar tornava-se problemático e arriscado (Sumida 2001, 102). De fato, para Mahan, a melhor estratégia era a obtenção do Comando do Mar através de uma batalha decisiva; em oposição, por exemplo, à guerra de corsário. Além disso, deter o Comando do Mar fornecia mais que a vitória na guerra; era a condição para a grandeza nacional (Mahan 2007).

O problema é que, tal qual definido por Corbett (2005), sua utilidade restringe-se a períodos de guerra e, tal qual manipulado por Mahan (2007), sua aplicação restringe-se a países de marinhas hegemônicas ou grandes potências. Generalizar o conceito e afirmar que todas as marinhas têm o objetivo de obter o Comando do Mar ignora que algumas nações têm objetivos menos ambiciosos em relação aos mares, como, por exemplo, assegurar a continuidade da exploração da pesca e da extração de recursos ou garantir a segurança da navegação em sua costa. Ademais, falar em controle das linhas de comunicação não capta o fator essencial das ZEEs de que a todo esse espaço se concede direitos soberanos e exclusivos para o Estado costeiro - e que toda essa área precisa ser vigiada; diferentemente de linhas de comunicação, que remetem à ideia de controle apenas de pontos nevrálgicos do trânsito de navios.

Diferentemente de autores que tentaram estender o uso de Comando do Mar para missões em tempos de paz (ver, por exemplo, Rubel 2012), e tendo em vista esse problema conceitual e teórico nos estudos marítimos, nosso objetivo principal é realizar um estudo da relação entre os fins e os meios navais no contexto contemporâneo de novas ameaças e de um novo marco jurídico-legal. O argumento desse trabalho é que os conceitos Segurança Marítima e Governança, se combinados, têm, ambos, a profundidade e o alcance necessários para preencher esse vazio da teoria de Estratégia Marítima, abrangendo não só as operações contra atores não-estatais, mas também a defesa da costa e das águas jurisdicionais marítimas contra atores estatais. As contribuições desse trabalho são: i) de nível teórico - a aplicação de um conceito já em voga para concorrer, mas não substituir, o uso de um conceito mais tradicional, inadequado para algumas 
das questões contemporâneas; e ii) de nível mais prático — a discussão sobre qual o arranjo de meios mais propenso a entregar os objetivos relacionados à segurança da ZEE.

$\mathrm{O}$ artigo segue organizado em quatro seções. Na segunda seção, que segue a essa introdução, será analisado o conceito de Segurança Marítima e as missões a ela relacionadas serão expostas. Na terceira seção, o conceito de Governança será desconstruído nos fatores que o viabilizam. Em ambos os casos, a argumentação será feita através de uma revisão bibliográfica. Na quarta seção, seguirá uma análise dos meios empregados, e de sua organização, para a proteção da ZEE, tendo como base o entendimento sobre Governança da Segurança Marítima, extraído das seções anteriores. Nesse momento, argumentar-se-á que há uma miríade de formas de organização dos meios para a gestão da ZEE que vai além da dicotomia entre marinhas e guardas costeiras. Por fim, o artigo encerra-se com algumas considerações finais sobre as implicações desse argumento.

\section{A AMBIGUIDADE DO CONCEITO DE SEGURANÇA MARÍTIMA E SUAS MISSÕES}

A Segurança Marítima é um conceito que se desenvolveu por duas razões internacionais paralelas. A primeira delas é estrutural e foi apresentada na introdução, isto é, o surgimento de um novo regime para os mares (Bueger 2015a; Basil Germond and Germond-Duret 2016; McNicholas 2008). A segunda razão para a consolidação do termo Segurança Marítima nos Estudos de Segurança Internacional foi a nova realidade estratégica do Ocidente após a Guerra Fria e o impacto de uma nova epistemologia (Feldt 2016, 12-13). Historicamente, Segurança é um termo aplicado prioritariamente para as relações conflituosas interestatais. A expansão horizontal (dimensões da segurança) e vertical (unidade de análise) do termo decorreu da influência da Teoria Crítica nas Relações Internacionais (Buzan and Hansen 2009). Paralelamente, nos anos 1990, os Estados Unidos reviram suas prioridades estratégicas, já que a inexistência de um competidor à altura garantia-lhe o controle das linhas de comunicação contra qualquer adversário. Optou-se, por isso, por uma estratégia de projeção de poder (United States 1994) contra Estados “párias” ou mal governados que pudessem ameaçar a ordem econômica. Em 2001, uma nova mudança ocorreu com os atentados em solo americano. A partir desse momento, o país passou a privilegiar um discurso de cooperação com seus aliados com o objetivo de policiar o sistema econômico contra ameaças à navegação (United States 2007). Nesse contexto, Segurança Marítima tornou-se a defesa do comércio marítimo global, da individualidade humana, de comunidades li- 
torâneas e até do meio ambiente marinho contra ameaças primordialmente não estatais relacionadas ao mar (Bruns 2017).

É nesse sentido que a literatura trata Segurança Marítima como um conceito de vários significados. É um conceito central que se relaciona com uma miríade de outros conceitos relacionados ao mar e faz a ponte de relação entre eles (Bueger 2015a). A consequência é que Segurança Marítima é ambígua porque trata simultaneamente de temas conflituosos e cooperativos (Till 2012, cap. 4). Ao mesmo tempo em que alguns aspectos da Segurança Marítima são fatores de atração na estratégia e nas políticas dos Estados, outras questões, como jurisdição e limites de ZEEs, dificultam o comprometimento coletivo. Dito de outra forma, o conceito opõe interesses inclusivos e interesses exclusivos (Klein 2011). Estes dizem respeito a práticas marítimas que beneficiam apenas a um Estado, em detrimento dos demais. Os interesses inclusivos são aqueles em que os problemas são coletivos e sua resolução traz benefícios a todos os Estados. A natureza dos oceanos para o direito internacional, um bem de uso comum, favorece a liberdade dos mares como regime. Pode-se associar, então, os interesses inclusivos com aqueles referentes à liberdade de navegação. Um dos componentes desse interesse é que os oceanos estejam livres de ameaças de todos os tipos, sejam estatais, sejam não estatais.

Entretanto, a cooperação em segurança marítima fica, na prática, dificultada pelas questões exclusivas: a desconfiança de Estados costeiros dos interesses dos demais países prejudicam soluções multilaterais. $\mathrm{O}$ avanço de noções de soberania sobre o ambiente marítimo torna mais sensível a ação de outros Estados em território de terceiros. Por exemplo, os Estados Unidos enfrentaram a resistência de Malásia e Indonésia na implantação da Iniciativa Regional de Segurança Marítima em 2004, devido à liberdade que aquele país teria para realizar patrulhas nas águas locais (Ho 2004, 1). Relacionadas às questões de soberania estão as diferentes visões referentes à CNUDM. Alguns países, ciosos em limitar a extensão da atuação dos demais em suas águas, defendem uma interpretação mais frouxa do regime de ZEE, que favorece maior controle sobre a jurisdição marítima. Outros, ou países de reduzida área marítima ou nações com amplo uso marítimo, defendem interpretação mais literal, em que a liberdade de atuação de terceiros nas ZEEs é maior (Holmes 2016).

A literatura tem cada vez mais priorizado o significado inclusivo em detrimento do exclusivo (Speller 2014, 151). Till (2018), por exemplo, cunhou o termo "boa ordem no mar" para contrapor este objetivo com a busca tradicional por poder marítimo. Segundo o autor, existe um grupo de países chamados de "pós-modernos", notadamente os ocidentais, representados por suas marinhas, que voltam seus esforços estratégicos para a garantia 
da segurança da globalização e do sistema econômico global. As marinhas pós-modernas seriam contrapostas às modernas, aquelas voltadas para a política de poder tradicional. Similarmente, Klein (2011) argumentou que enxergar Segurança Marítima como a proteção contra ameaças não-estatais é uma das ferramentas para aprimorar o direito internacional do mar, promovendo interesses inclusivos de liberdade de navegação em detrimento dos exclusivos.

A ideia de que Segurança Marítima é inclusiva, entretanto, é deliberada, visto que a ambiguidade natural do termo não é eliminada. A restrição a ameaças não-estatais não evita que haja conflitos nas formas e nos objetivos referentes ao combate cooperativo. Da mesma forma que estender o Comando do Mar para a totalidade do espectro de missões das forças navais enfraquece o conceito, a divisão binária entre Comando do Mar, relativo às relações interestatais, e Segurança Marítima, relativa às ameaças não estatais, é insuficiente porque não leva em consideração a complexidade política da tarefa de gerir a ZEE. Para nossos fins, portanto, Segurança Marítima abrange um amplo leque de missões. Estas podem ser divididas em três grupos menores: missões de salvaguarda marítima, missões de interdição e missões de Defesa. A Figura 1, a seguir, ilustra as missões de Segurança Marítima e de Comando do Mar.

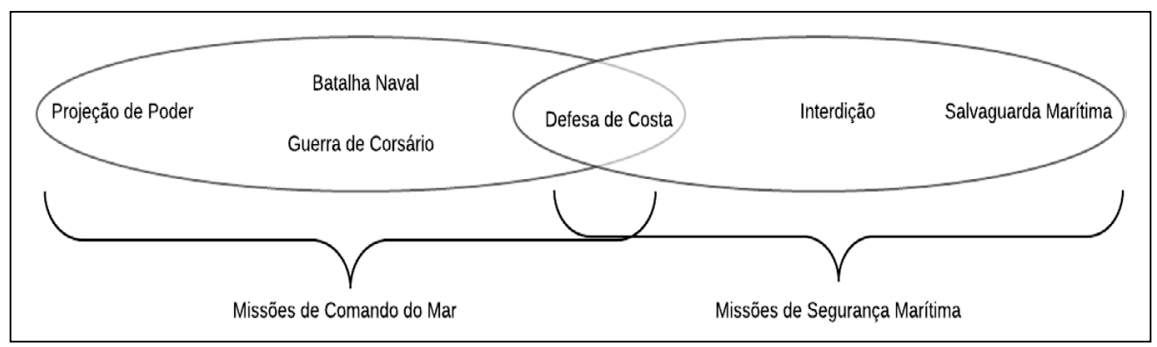

Figura 1 - As missões das forças navais.

Fonte: elaboração do autor.

O conjunto de ameaças que um Estado enfrenta no mar direciona as missões de suas forças de segurança marítima. Ameaças tradicionais (estatais) podem exigir missões de segurança nacional, seja em caso de guerra, seja quando há competição marítima interestatal. Defesa de Costa é a missão relacionada à Segurança Marítima realizada durante guerras. Considera-se a Defesa de Costa como a missão que interliga o Comando do Mar àquele conceito. Isso porque Defesa de Costa limita-se ao litoral, isto é, à zona territorial marítima; porque, assim como o policiamento marítimo, depende 
da realização de patrulhas e vigilância, e porque há coincidência entre os meios necessários para a sua consecução e aqueles necessários ao policiamento - como navios-patrulha, sensores e radares. Defesa da soberania e da jurisdição marítima é outra missão relacionada à Defesa no contexto da Segurança Marítima. Ela diz respeito a incursões de navios militares, navios estatais ou navios privados atuando em consonância com os interesses de seu Estado na ZEE de um terceiro país. Com a formalização das ZEEs, a defesa da soberania e da jurisdição marítima vêm tornando-se cada vez mais frequentes atribuições das forças de segurança marítima.

Em uma espécie de linha divisória entre ameaças à segurança nacional e ameaças criminais está o terrorismo. Este é uma tática que pode ser usada por grupos insurgentes ou, isoladamente, por indivíduos. Os grupos insurgentes possuem objetivos políticos e podem fazer uso, além do terrorismo, de táticas de guerrilha (Murphy 2007, 63). O uso do mar para esses grupos é auxiliar, já que seu objetivo maior só pode ser alcançado em terra. Devido ao seu viés político, o combate às insurgências geralmente fica a cargo de forças militares, cabendo a guardas costeiras e forças paramilitares ou policiais as tarefas de combate e prevenção, como patrulhas e vigilância (Anderson 2010; Bueger, Stockbruegger, and Werthes 2011; Forbes 2017).

As ameaças menos militarizadas iniciam com a consideração do crime organizado no mar. Este é uma organização contínua, com fins de lucro privado por atividades ilícitas, geralmente com o monopólio de alguma mercadoria ou serviço, e uso ou ameaça do uso da força e corrupção como meios para sustentar a permanência das atividades (Albanese 2014, 3; Duarte, Marcondes, and Carneiro 2019). Contra esses grupos realizam-se "Em apoio à imposição da lei, atividades conduzidas para desviar, interromper, atrasar, interceptar, embarcar, deter ou destruir, sob a autoridade legal, navios, veículos, aeronaves, pessoas, cargas e dinheiro.” (United States 2010, 117, tradução nossa). A interdição se materializa com o embarque, a visita, a busca e a captura de pessoas, cargas e embarcações. Como entre as ações ilegais possíveis estão a pirataria, o tráfico de drogas, a pesca ilegal e o contrabando de mercadorias e de pessoas e como essas atividades não são igualmente violentas, são operacionalmente diferentes e podem envolver diretamente pessoas inocentes ou não ameaçadoras, não é possível falar em uma mesma missão de interdição para todas, ainda que todas sejam combatidas pelo policiamento. Assim, são diferentes entre si a proteção dos recursos marítimos (pesca, hidrocarbonetos e infraestrutura), a proteção das fronteiras (imigração, contrabando de mercadorias e tráfico de drogas) e a segurança da navegação (pirataria e terrorismo).

$\mathrm{O}$ combate à poluição separa as missões de policiamento de ilícitos, englobadas pela interdição marítima, daquelas de prevenção e resposta 
de acidentes, englobadas pela salvaguarda marítima, haja vista que o ato poluente pode ser intencional ou acidental. A poluição é tratada como ameaça à segurança marítima visto que, a fim de que as riquezas marítimas possam ser aproveitadas em todo o seu potencial, precisa-se que o ambiente marinho seja palco de atividades humanas sustentáveis e condizentes com o seu ecossistema.

Missões de salvaguarda marítima lidam com a ameaça de acidentes (Mejia 2002, 28). Essas missões tratam da supervisão do tráfego marítimo, da verificação da adequação de navios a normas nacionais e internacionais, da gestão dos auxílios à navegação, da investigação de acidentes, etc. Uma vez concretizando-se o acidente, as forças de segurança marítima devem ter de realizar missões de busca e salvamento. Como concentram-se na prevenção de acidentes e na resposta a ocorrências, essas missões não se relacionam com o policiamento armado, típico das missões de interdição, mas com atividades que podem ser aproximadas do policiamento administrativo — inspeção, controle, regulação — ou, como a analogia de Germond (2015,44), com "bombeiros marítimos", por sua postura de prevenção e resgate.

\section{A GOVERNANÇA COMO CONDIÇÃO PARA A SEGURANÇA MARÍTIMA}

A Segurança Marítima, ou boa ordem dos mares, é uma condição para que os Estados alcancem todo seu potencial econômico através da exploração das Zonas Econômicas Exclusivas (Bueger 2015b, 39). Para que um Estado fique livre das ameaças específicas a sua individualidade histórica e geográfica, é preciso que haja o exercício efetivo da governança desse ambiente. Governança é governar sem governo por meio da ação conjunta de atores diversos, estatais ou não (Finkelstein 1995, 369). Portanto, não deve ser confundido com um regime internacional. Aquela ocorre preferencialmente dentro de um regime, mas não necessariamente. Este trata de redes de normas e instituições compartilhadas intersubjetivamente que funcionam como a moldura em que se desenvolvem as ações de todos os atores. Já a governança diz respeito a um "comportamento intencional" orientado para um objetivo (Rosenau 1992, 4). Note-se que não é o mesmo que falar em governo, uma vez que este implica em autoridade central com legitimidade formal, enquanto governança pode acontecer com entendimentos coletivos informais. Nesse sentido é que falar em governança da ZEE é possível, já que a autoridade central não exerce soberania sobre a área - apenas detém os direitos de exploração — , deve levar em consideração uma miríade de atores que transitam no local e, em alguns casos, deve responder ao arcabouço institucional do regime marítimo internacional. 
A Governança da Segurança Marítima significa a capacidade de manter a segurança no ambiente oceânico realizando o patrulhamento, a vigilância e a "resposta" - esta última, a aplicação da lei doméstica e internacional (Bateman 2016b, 8). Estas são tarefas complexas graças à transnacionalidade do ambiente, às múltiplas jurisdições que se sobrepõem, à interconectividade das atividades realizadas e à relação estreita entre os acontecimentos em terra e sua reverberação no ambiente marinho (Bueger and Edmunds 2017, 1299-1302). A governança e as missões que a concretizam, vistas acima, podem ocorrer em três níveis: nacional, regional e internacional (Beirão 2017). Na verdade, essa característica em si já torna desafiadora a tarefa de gerir o espaço marítimo (Germond 2018). A ação nacional, se se quer politicamente viável, precisa adequar-se à realidade da região, reconhecendo os interesses de atores vizinhos - e dos Estadosusuários que trafegam por ali. Uma governança internacional de águas regionais é complicada não só pelo tradicional confronto de interesses entre navegação e exploração, mas também pela dificuldade em sustentar-se capacidades de vigilância e resposta por atores extrarregionais sem o comprometimento de atores locais. Por isso, a desconfiança dos atores locais dificulta a coordenação multilateral, haja vista o tradicional confronto político entre Estados costeiros e Estados usuários das linhas marítimas.

A componente basilar sobre a qual assenta-se a governança marítima é a vigilância (Pozo et al. 2010). O conceito que descreve a prática é a Consciência do Domínio Marítimo (MDA, em inglês). Esse termo surgiu com a Guarda-Costeira dos Estados Unidos ainda nos anos 1990, e seu objetivo era integrar o planejamento de operações de busca e salvamento, imposição da lei e de proteção ao meio ambiente (Murphy 2008, 22). Oficialmente, os Estados Unidos descrevem a MDA como "o efetivo conhecimento de tudo associado ao domínio marítimo global que possa impactar a segurança, salvaguarda, economia ou meio ambiente dos Estados Unidos" (United States 2005, ii, tradução nossa).

Importante, o domínio marítimo é composto por "Todas áreas e coisas de, sobre, sob, relacionadas, adjacentes ou fronteiriças a um mar, oceano ou outra hidrovia navegável, incluindo todas as atividades, infraestruturas, pessoas, cargas, navios e outros, relacionados ao mar" (United States 2005, i, tradução nossa). Essa ampla definição imediatamente traz o problema da real viabilidade (e necessidade) de se lidar com uma quantidade de informação dessa monta. É absolutamente necessário que haja a capacidade em se distinguir quais informações constituem ameaça e quais correspondem à normalidade das atividades marítimas (Boraz 2009, 141). Parte da solução está no cruzamento, fusão e análise de dados (Friedman 2009). Isso, que por si só já é um desafio, é tornado ainda mais complexo por agentes 
marítimos que não estão dispostos a compartilhar suas informações ou que burlam os sistemas, mascarando ou alterando propositalmente seus dados. Contra isso, a MDA exige redundância na cobertura, para que sistemas que independam da boa vontade de criminosos ou indivíduos mal-intencionados possam compensar sistemas assim dependentes (Murphy 2008, 23). Outra solução é a delimitação geográfica e funcional clara do centro responsável pela coleta de informações, a fim de diminuir a monta de informação disponível (Doorey 2016, cap. 8).

A importância da vigilância e da Consciência de Situação Marítima decorre da centralidade da informação e da inteligência para a gestão das diversas atividades marítimas. De fato, alguns autores afirmam que a MDA nada mais é que a extensão marítima de atividades de inteligência policial para a prevenção de crimes (Doorey 2016, cap. 8). Por isso, a coleta e a disseminação da informação são tão centrais na cooperação em segurança marítima. Como o ambiente marítimo é muito extenso e complexo, um panorama maior dos fatos só é possível graças às práticas de compartilhamento. Entretanto, Bueger (2015c) identifica três desafios a serem superados. Primeiro, a disseminação da informação não pode ignorar os possíveis conflitos entre os atores envolvidos. Segundo, deve-se estabelecer o tipo de informação, o que envolve definir se informações potencialmente sigilosas estão envolvidas. Terceiro, o dado por si só não informa nada; é preciso criar uma interpretação deste (preferencialmente coletiva). Ao acontecer no âmbito cooperativo, o compartilhamento de informações pode diminuir a contradição de, em certos casos, prejudicar a segurança nacional do Estado costeiro. Isso porque, em se tratando de ameaças transnacionais, o interesse comum em combatê-las leva ao ganho coletivo de compartilhamento de informações (Klein 201 1, 212). É fundamental a existência de procedimentos regionais de coleta e distribuição de dados e informações relacionados à atividade de navegação, por exemplo. Também é importante que a troca de informações vá além do mundo virtual, contando com agentes físicos capazes de coordenar a troca e a análise dos dados (Boraz 2009, 144).

O patrulhamento e a resposta são as atividades da Governança da Segurança Marítima subsequentes à vigilância. São subsequentes porque ambas necessitam do suporte da vigilância para que possam funcionar efetivamente. $\mathrm{O}$ patrulhamento diferencia-se da vigilância por seu caráter de presença, isto é, enquanto essa é realizada por satélites, sensores e eventualmente aeronaves, aquele é realizado por aeronaves e embarcações preferencialmente de forma coordenada e sistemática. Ademais, a vigilância é limitada em sua capacidade de acessar as intenções das embarcações (Ong and Ho 2005). Ela pode mostrar dados que tornem certos navios suspeitos, mas a confirmação só é possível com a presença física de agentes capazes de 
investigar a atividade suspeita. Além disso, a presença consequente do patrulhamento é preventiva, no sentido de que serve como medida dissuasora de atividades criminosas. As patrulhas, no entanto, dificilmente abrangem a totalidade do espaço marítimo: em alguns casos a dimensão é um impeditivo; em outros, o custo-benefício não compensa, haja vista que a pouca circulação de embarcações em certas áreas e a distância destas do ambiente terrestre torna-as pouco suscetíveis a atividades ilegais. Por isso, há concentração da atuação da força de segurança marítima: recursos e interesses dos Estados ficam concentrados, assim o patrulhamento pode se concentrar em área reduzida, com eventuais incursões a áreas maiores da ZEE (Morgan 1994, 370). Nesse sentido, a criação de zonas de patrulhamento é um instrumento administrativo útil para a determinação dos pontos de maior interesse ou maior vulnerabilidade (Ong and Ho 2005, 3). Um outro benefício decorrente de zonas de patrulhamento é o impedimento de patrulhas redundantes, quando existe mais de uma entidade com responsabilidades marítimas, que percorrem o mesmo espaço com objetivos individualizados (Bateman 2016b, 163). A delegação de zonas específicas facilita a atribuição das missões.

A resposta é a sequência natural do patrulhamento, assim que as forças navais responsáveis se deparam com a prática ilegal e confirmam sua ocorrência. A fase da resposta coincide com a interdição marítima, isto é, a aproximação, perseguição, embarque, inspeção, busca e eventual apreensão de embarcações, cargas e pessoas. As regras de engajamento da fase de resposta constituem-se no uso mínimo da força, sendo que esta deve ser usada em situações inevitavelmente necessárias de forma razoável e proporcional (Shearer 1998, 440-41). Naturalmente, a política de uso da força pode variar conforme a natureza da ameaça: forças navais que lidam com piratas ou insurgentes devem esperar maior resistência do que aquelas que lidam com pesca ilegal. Além de uma resposta a ações ilegais nas ZEEs, não se pode perder de vista que essa fase também é uma reação a acidentes marítimos, através de missões de busca e salvamento.

Com essa moldura em mente, pode-se passar para a discussão dos meios para se responder ao questionamento: qual o arranjo de meios mais adequados para a realização dos objetivos estatais referentes à segurança de suas áreas jurisdicionais marítimas?

\section{OS MEIOS NAVAIS EMPREGADOS PARA A GOVERNANÇA DA SEGURANÇA MARÍTIMA}

A entrada em vigor da CNUDM gerou, no século XXI, a definitiva consolidação das guardas-costeiras, dedicadas ao policiamento marítimo (Speller 2014, 150). São forças com pouca uniformidade internacional, já 
que o que as unifica conceitualmente são as missões de policiamento no ambiente marítimo doméstico: sua essência está, pois, no objetivo para o qual foi constituída (Paleri 2009, 48). Entretanto, a ideia de que guardas costeiras são as forças de policiamento e marinhas as forças de guerra é uma divisão binária artificial que não corresponde à realidade. Na prática, existem formas variadas de combinação e organização dessas forças, assim como seu inter-relacionamento também é variável (Bateman 2016a; Till 2009). Porque pode envolver a missão de Defesa de Costa, a Governança da Segurança Marítima exige capacidades de defesa que vão além daquelas possuídas por guardas costeiras (Wilson 2016). Contudo, uma vez que aquela se restringe a zonas costeiras, as capacidades necessárias para Projeção de Poder e controle indisputado das linhas de comunicação costeiras, geralmente associadas ao Comando do Mar, não são requisitos para a consecução dos objetivos relacionados à Governança da Segurança Marítima.

Como argumentado, então, as guardas costeiras, da forma como descritas idealmente, são parte importante no que diz respeito à organização dos meios navais para a gestão da segurança marítima, mas não são as únicas possibilidades. Para identificar as possibilidades de organização, parte-se da proposta de Till (2009, 315-18), que vislumbrou quatro modelos de conformação institucional para realização das missões de segurança marítima, conforme a Figura 2, a seguir.

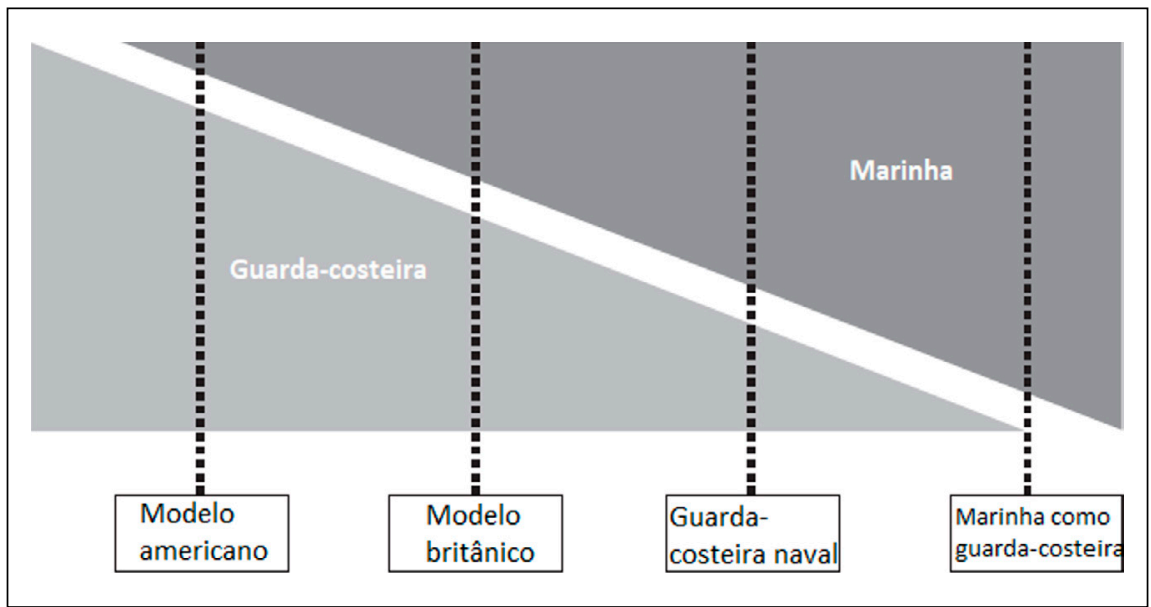

Figura 2 - Os modelos de organização das forças de segurança marítima, segundo Geoffrey Till.

Fonte: adaptado de Till $(2009,315)$. 
Os modelos variam no grau de envolvimento das marinhas em missões de Segurança Marítima. Em um extremo, as guardas-costeiras são responsáveis por quase a totalidade das atividades de gestão da segurança. Esse modelo, que distingue claramente a guarda-costeira da marinha, é baseado na Guarda-Costeira dos Estados Unidos. A marinha fica responsável pela Projeção de Poder e controle de linhas de comunicação distantes, enquanto a guarda costeira monopoliza o policiamento.

Geoffrey Till chamou de modelo britânico aquele em que não existe uma única agência responsável pelas funções de segurança marítima. Nele, as marinhas e outras forças militares podem controlar boa parte dos ativos utilizados para atividades de patrulhamento, e outras agências complementam as tarefas. Nesses casos, não existe uma guarda-costeira propriamente dita, mas um conjunto de forças que atuam de forma independente em missões policiais. É possível, nessas situações, a existência de agências civis responsáveis por inspecionar navios de pesca; forças aduaneiras, principalmente portuárias; algum tipo de ramificação marítima das forças de segurança pública e agências exclusivamente para a salvaguarda da navegação. Embora o autor faça a apologia a esse modelo, por esse ser o modelo britânico, a pulverização das funções de guarda-costeira gera o risco de duplicação de atividades e gastos desnecessários, como o patrulhamento duplo de uma mesma área com objetivos diferentes (Bateman 2005, 15). Em um terceiro modelo, de guardas-costeiras navais, a marinha passa a ganhar proeminência decisória na gestão marítima quando a agência ou serviço responsável possui existência própria, mas é subordinada organizacionalmente à marinha. Finalmente, no extremo oposto ao modelo americano, a marinha detém o controle da segurança marítima quando cumpre todas as funções de guardas-costeiras. Podem ser marinhas que se dividem entre o Comando do Mar e a Segurança Marítima ou marinhas que atuam exclusivamente na gestão da ZEE (Mière 2014).

Partindo de Till (2009), Bateman (2016a) também construiu modelos de organização, embora seu modelo seja mais direcionado a compreender o grau de centralização das forças de segurança marítima do que necessariamente a relação entre a agência civil e a marinha. Em um modelo de agências únicas pode haver uma marinha que realize tanto missões bélicas quanto missões policiais ou, em países pequenos, exclusivamente uma marinha ou uma guarda-costeira que realize missões policiais. $\mathrm{O}$ modelo de agências separadas, mais comum em países grandes, traz uma marinha convivendo com uma guarda-costeira, que pode ser mais ou menos militarizada. Por fim, o modelo híbrido corresponde a situações em que a marinha compartilha as missões com a guarda-costeira, e esta pode não ser centralizada, mas pulverizada em mais de uma agência. 
É preciso chamar a atenção para alguns aspectos. As forças que realizam as missões de Segurança Marítima variam em termos de sua centralização. Quanto maior o interesse geopolítico de um país, maior a tendência de centralização e de concentração das missões de Governança da Segurança Marítima nas guardas costeiras (Bateman 2016a). Isso pode ser explicado, em parte, pelo fato de que países com questões de segurança mais proeminentes tenderão a ter marinhas mais voltadas para o controle das linhas de comunicação e para a projeção de poder. Por isso, veem na criação de guardas costeiras uma possibilidade de liberar-se de tarefas menores. A Ásia-Pacífico vê, nos últimos anos, países relativamente pequenos, como o Vietnã, criarem forças desse tipo porque a geopolítica dessa região impele que marinhas sejam voltadas para o combate (Mière 2011; Becker-Weinberg 2016). A pulverização tende a acontecer com países onde o dilema de segurança não é tão intenso e forças de cunho auxiliar à marinha não sejam imperiosas. Exemplos nesse sentido são Canadá e Reino Unido (Edmonds 2016). Nesses casos, não existe uma guarda costeira centralizada, mas um conjunto de forças que atuam de forma independente em missões policiais. É possível, nessas situações, a existência de agências civis responsáveis por inspecionar navios de pesca; forças aduaneiras, principalmente portuárias; algum tipo de ramificação marítima das forças de segurança pública e agências para a salvaguarda da navegação. O risco é que haja sobreposição de patrulhamento, ou seja, a realização de patrulhas por forças diferentes com objetivos diferentes em uma mesma área, gerando custos desnecessários.

O segundo ponto é o grau de militarização das forças de segurança marítima (Lutterbeck 2004). Se marinhas realizam as missões, pode-se concluir que a gestão da segurança marítima como um todo será militarizada, e isso é ainda mais intenso se essas marinhas também tiverem funções de defesa de costa ou projeção de poder. O problema nesse viés é que as ZEEs não se configuram como áreas de soberania e seu regime corresponde ao de águas internacionais. Assim, o contato com navios estrangeiros com o uso de navios de guerra pode ser diplomaticamente bastante problemático. Entretanto, a militarização das forças de Segurança Marítima também ocorre com guardas costeiras e agências civis (L. J. Morris 2017; Mière 2011). Em um extremo, elas podem estar subordinadas ao Ministério da Defesa - configurando-se como serviços militares — ou a outras forças paramilitares (L. J. Morris 2018). Ademais, mesmo sob o guarda-chuva civil podem ser militarizadas em seus costumes, reproduzindo a cultura militar.

Outro ponto da organização dos meios é a difícil diferenciação institucional entre guardas costeiras e polícias marinhas (Paleri 2009). Esta última geralmente é o ramo marítimo de forças policiais e é paramilitar quan- 
do deriva de gendarmarias - também chamadas de forças constabulares (França 2018). Também guardas costeiras podem ser vinculadas a forças terrestres e paramilitares. Entretanto, polícias marinhas apresentam um alcance geográfico limitado e, tendo em vista a segurança da ZEE, são insuficientes, por si só, para esse objetivo (Button et al. 2008). Geralmente realizam apenas a garantia da lei e da ordem em hidrovias internas ou costeiras. Nesse sentido, empiricamente existe alguma distinção entre guardas costeiras e polícias marinhas, as últimas sendo mais capazes em termos de plataformas navais e mais demandadas em termos de missões. Conceitualmente, portanto, a diferenciação pode ser útil para a análise porque informa as capacidades de Governança da Segurança Marítima.

A execução por marinhas das missões de Governança da Segurança Marítima relacionadas a ameaças não estatais, ou seja, as missões de interdição e salvaguarda marítima, guarda alguns problemas operacionais. As marinhas são forças criadas para a condução da guerra. Como tal, o treinamento esperado de seus soldados e oficiais envolve o exercício de tarefas e de técnicas que serão reproduzidas em situação caótica com curto tempo para reflexão. A atividade de aplicação da lei, por sua vez, envolve um conjunto de conhecimentos e habilidades que pouco convergem com aqueles requisitados pelo ambiente da guerra. Assim, o uso de soldados para o policiamento marítimo pode acarretar dois problemas opostos: ou o soldado aplicará o treinamento militar de forma inapropriada contra criminosos civis ou o treinamento em operações de Segurança Marítima o tornará deficiente na execução das tarefas militares (Antonio 2018).

Nessa mesma linha, essas atividades apresentam plataformas navais e armamentos específicos para suas missões. $\mathrm{O}$ caráter da guerra moderna, baseado nas tecnologias da informação e nos mísseis, elevou em muito a sofisticação dos equipamentos e dos sistemas. Não só o treinamento, conforme mencionado acima, tornou-se mais demandante, como os custos para a aquisição de tais meios aumentaram consideravelmente (Till 2009, 122). Contudo, a utilidade de equipamentos altamente complexos restringe-se a grandes marinhas e conflitos de alta intensidade entre grandes potências. Forças de segurança marítima que atuem sob a Governança da Segurança Marítima não possuem requisitos operacionais por tecnologia de ponta, mesmo com a missão de Defesa de Costa. Por isso, o uso de grandes navios embarcados com sistemas tecnologicamente avançados não é nem financeiramente sustentável nem defensável aos olhos da opinião pública.

Além disso, a interação entre os atores na ZEE vai inevitavelmente transmitir alguma mensagem: Estados podem protestar diplomaticamente com a demonstração excessiva e desnecessária de força seja contra navios militares que trafegam pacificamente seja contra navios civis, criminosos 
ou não (Mière 2014). Então, se uma marinha deseja adequar seus meios ao contexto da ZEE, será preciso optar por navios relativamente menores conhecidos como navios-patrulha, com armas de pequeno calibre e velocidade mais elevada - especificação técnica condizente com a possível perseguição a embarcações velozes (Willett 2018). Isso conduz à necessidade de, mais cedo ou mais tarde, haver uma escolha pela marinha sobre qual seu perfil desejado - marinha de projeção de força com delegação do policiamento marítimo para outra força nacional, ou marinha com capacidades de defesa e policiamento da costa. Naturalmente, surge aí um dilema estratégico e orçamentário, visto que mesmo marinhas de países desenvolvidos têm dificuldade em cobrir todo o leque de missões (Till 2018).

A respeito do arcabouço legal que envolve as atividades das marinhas, a complexidade dos objetivos de Segurança Marítima e de Comando do Mar torna proibitiva a delegação de tarefas tão divergentes a um mesmo oficial ou soldado. Desde o surgimento da CNUDM, as possibilidades legais são tantas em contextos geográficos (por exemplo, sobreposição de ZEEs) e humanos (diferenciação entre tráfico de pessoas e contrabando de migrantes) tão individuais que o conjunto de conhecimentos técnicos-legais para essas questões dificilmente pode ser tratado em conjunto com o direito da guerra naval (Bateman 2011). É preciso que cada arcabouço legal seja distribuído em agentes especializados. Outra questão legal lida com as limitações constitucionais do uso de militares em operações de policiamento, já que o uso de militares contra civis pode ter implicações sociais e políticas (Antonio 2018).

\section{CONCLUSÃO}

O trabalho procurou questionar a generalização do termo Comando do Mar, entendido como projeção de poder, à totalidade dos países e de suas forças navais. Algumas nações, por limitações geográficas, políticas ou econômicas, têm interesses que se restringem à segurança e defesa de suas ZEEs ou áreas costeiras. A consequência é que o conjunto de missões e cenários de emprego tornam-se mais limitados em termos de uso da força. Para contemplar essas situações usou-se o conceito de Governança da Segurança Marítima, cujas missões variam da defesa de costa, em um extremo, à salvaguarda marítima em outro. A aplicação de Governança da Segurança Marítima serve justamente para redimensionar o conjunto de objetivos de algumas nações no ambiente marítimo.

Assim, a discussão coloca em questão quais os meios realmente necessários para a consecução desses objetivos. Em suma, o intuito é reconhecer que, dados os recursos escassos, as forças de segurança e defesa precisam ater-se à consecução de objetivos nacionais, com as ameaças e as ambi- 
ções nacionais servindo de parâmetro. Países com rivalidades interestatais claras, principalmente grandes potências, tendem a constituir marinhas e guardas costeiras com delimitações mais claras. Países pequenos, guardas costeiras ou marinhas que atuam como guardas costeiras. Países ou sem rivalidades claras ou sem recursos financeiros abundantes precisam encontrar, dentre as possibilidades vistas acima, quais arranjos servem melhor a seus propósitos. Como visto, o uso de capacidades e soldados preparados para o conflito de alta intensidade no policiamento marítimo apresenta uma série de problemas. Guardas costeiras têm se apresentado como as forças do policiamento marítimo por excelência, amalgamando os equipamentos adequados e o conhecimento necessário. Cabe salientar que existem modelos diversos de organização dessas forças e que sua constituição não se configura necessariamente como uma afronta à existência das marinhas no arcabouço institucional de um país. Ambas podem coexistir em um arranjo cooperativo que integre o policiamento marítimo com a defesa da costa e da soberania sobre o território marítimo.

A Defesa, por meio da missão de Defesa de Costa, é componente importante da Governança da Segurança Marítima. Onde não há recursos para a concepção de duas forças marítimas, a opção por capacidades suficientes de Defesa de Costa - como mísseis antinavio, radares, artilharia costeira, submarinos convencionais, entre outros - associada a capacidades de policiamento - pessoal treinado, navios-patrulha oceânicos - e um arcabouço de cooperação com os demais países da região pode substituir a noção de marinhas altamente tecnológicas e voltadas para o controle do alto-mar. Por isso, a proposição desse conceito não equivale a diminuir a importância da marinha frente às guardas costeiras. Pelo contrário, marinhas seguem sendo peças-chave na gestão dos oceanos. Contudo, cabe reconhecer a necessidade de reorganização das capacidades navais frente a novos objetivos para que se redimensione a atuação de marinhas e outras forças marítimas.

\section{REFERÊNCIAS}

Aguilar, Andrés. 1976. "Introductory note". Working papers of the Plenary. New York. http://legal.un.org/docs/?path=../diplomaticconferences/1973_los/docs/ english/vol_5/a_conf62_wp8_rev1_part3.pdf\&lang=E.

Albanese, Jay S. 2014. Organized Crime: From the Mob to Transnational Organized Crime. 7. ed. Londres: Anderson.

Anderson, Elliot A. 2010. "It's a Pirate's Life for Some: The Development of an Illegal Industry in Response to an Unjust Global Power Dynamic". Indiana Journal of Global Legal Studies 17, no. 2: 319-39. 
Antonio, Roberta Lopes da Cruz. 2018. "Desafios da Marinha do Brasil na promoção da segurança nacional: reflexos de uma crise nacional multidimensional". Revista da Escola de Guerra Naval 24, no. 1: 148-77. https://revista.egn.mar.mil. br/index.php/revistadaegn/article/view/664.

Bateman, Sam. 2005. “Maritime 'Regime' Building”. In The Best of Times, the Worst of Times: Maritime Security in the Asia-Pacific, edited by Joshua Ho and Catherine Raymond, 259-275. Singapore: World Scientific.

2011. 'Solving the 'Wicked Problems' of Maritime Security: Are Regional Forums up to the Task?". Contemporary Southeast Asia: A Journal of International and Strategic Affairs 33, no. 1: 1-28. https://muse.jhu.edu/article/436965.

2016a. "Managing Maritime Affairs: The Contribution of Maritime Security Forces". In International Order at Sea: How It Is Challenged. How It Is Maintained, edited by Jo Inge Bekkevold, and Geoffrey Till, 261-82. Londres: Springer.

2016b. "Maritime security governance in the Indian Ocean region". Journal of the Indian Ocean Region 12, no. 1: 5-23.

Becker-Weinberg, Vasco. 2016. "Improving Maritime Safety and Security in the South China Sea". In Routledge Handbook of Naval Strategy and Security, edited by Joachim Krause, and Sebastian Bruns, 58-76. New York: Routledge.

Beckman, Robert, and Tara Davenport. 2012. "The EEZ Regime: Reflections after 30 Years". In LOSI Conference Papers. Seul: Law of the Sea Institute, Berkeley.

Beirão, André Panno. 2017. "Why Not Eminently Maritime UN Peacekeeping Operations?”. Contexto Internacional 39, no. 2: 245-62. https://doi.org/10.1590/ s0102-8529.2017390200003.

Boraz, Steven C. 2009. "Maritime Domain Awareness: Myths and Realities". Naval War College Review 62, no. 3: 137-46. https://search.proquest.com/docview/205943026/abstract/4682A16A1DF04A87PQ/1.

Bruns, Sebastian. 2017. US Naval Strategy and National Security: The Evolution of American Maritime Power. 1. ed. Abingdon, Oxon; New York, NY: Routledge.

Bueger, Christian. 2015a. "What is maritime security?". Marine Policy 53: 159-65.

2015b. "Learning from piracy: future challenges of maritime security governance". Global Affairs 1, no. 1: 33-42. https://doi.org/10.1080/23340460.201 5.960170 . 
2015c. "From Dusk to Dawn? Maritime Domain Awareness in Southeast Asia”. Contemporary Southeast Asia 37: 157-82. https://doi.org/10.1355/cs37-2a.

Bueger, Christian, and Timothy Edmunds. 2017. "Beyond Seablindness: A New Agenda for Maritime Security Studies”. International Affairs 93, no. 6: 1293-311. https://doi.org/10.1093/ia/iix 174.

Bueger, Christian, Jan Stockbruegger, and Sascha Werthes. 2011. "Pirates, Fishermen and Peacebuilding: Options for Counter-Piracy Strategy in Somalia". Contemporary Security Policy 32, no. 2: 356-81. https://doi.org/10.1080/1352326 0.2011 .590359 .

Button, Robert, Irv Blickstein, Laurence Smallman, David Newton, Michele Poole, and Michael Nixon. 2008. Small Ships in Theater Security Cooperation. Monographs, National Defense Research Institute. https://www.rand.org/pubs/monographs/ MG698.html.

Buzan, Barry, and Lene Hansen. 2009. The Evolution of International Security Studies. Cambridge, UK; New York: Cambridge University Press.

Corbett, Julian. 2005. Some principles of maritime strategy. [s.1]: Project Gutenberg. http://www.gutenberg.org/files/15076/15076-h/15076-h.htm\#Page_91.

Doorey, Tymothy. 2016. "Maritime Domain Awareness". In Global Responses to Maritime Violence: Cooperation and Collective Action, edited by Paul Shemella, chap. 8. Stanford, California: Stanford Security Studies. Kindle.

Duarte, Érico, Danilo Marcondes, and Camilo Carneiro. 2019. "Facing the Transnational Criminal Organizations in the South Atlantic". In Maritime Security Challenges in the South Atlantic, 11-40. Cham: Palgrave Macmillan.

Edmonds, Graham. 2016. Protection of the UK's EEZ and Territorial Seas: Does the Government care? UKNDA Discussion Paper. Portsmouth: National Defence Association. http://www.cpahq.org/cpahq/cpadocs/UKNDA\%20EEZ\%20and\%20 Territorial\%20Seas.pdf.

Feldt, Lutz. 2016. “The Complex Nature of Today’s Maritime Security Issues”. In Routledge Hanbkook of Naval Strategy and Security, edited by Joachim Krause, and Sebastian Bruns, 11-26. New York: Routledge.

Finkelstein, Lawrence S. 1995. "What Is Global Governance?”. Global Governance 1, no. 3: 367-72. http://www.jstor.org/stable/27800120.

Forbes, Glenn. 2017. "Replicating Success? A Military Response to Maritime Piracy, the Somalia Experience". In Militarised Responses to Transnational Organised Crime: the War on Crime. New York: Palgrave Macmillan. 
França, Rafael. 2018. "Por uma nova gestão securitária de fronteiras no Brasil: riscos e desafios". Tese (Doutorado). Porto Alegre: Universidade Federal do Rio Grande do Sul.

Friedman, Norman. 2009. Network-Centric Warfare: How Navies Learned to Fight Smarter Through Three World Wars. Annapolis, Md.: Naval Institute Press.

Germond, Basil. 2015. The Maritime Dimension of European Security: Seapower and the European Union. [s.1]: Palgrave Macmillan UK.

2018. "Clear Skies or Troubled Waters: The Future of European $\overline{\text { Ocean }}$ Governance”. European View 17, no. 1: 1-8. https://doi. org/10.1177/1781685818761594.

Germond, Basil, and Celine Germond-Duret. 2016. "Ocean governance and maritime security in a placeful environment: The case of the European Union". Marine Policy 66 (April): 124-31. https://doi.org/10.1016/j.marpol.2016.01.010.

Ho, Joshua. 2004. "Operationalising The Regional Maritime Security Initiative". IDSS Commentaries. Singapore: Rajaratnam School of International Studies. https://www.rsis.edu.sg/rsis-publication/idss/614-operationalising-the-regional/\#.XUspnuhKjIV.

Holmes, Caitlyn. 2016. "Indian Ocean Security: Developments in Ocean Law, Trade, and Resources". In Routledge Handbook of Naval Strategy and Security, edited by Joachim Krause, and Bruns, 88-102. New York: Routledge.

Klein, Natalie. 2011. Maritime Security and the Law of the Sea. Oxford: Oxford University Press.

Lutterbeck, Derek. 2004. "Between Police and Military: The New Security Agenda and the Rise of Gendarmeries". Cooperation and Conflict 39, no. 1: 45-68. https:// doi.org/10.1177/0010836704040832.

Mahan, Alfred T. 2007. The Influence of Sea Power Upon History, 1660-1783. [s.1]: Project Gutenberg. http://www.gutenberg.org/ebooks/13529.

McNicholas, Michael. 2008. Maritime Security an Introduction. Amsterdam; Boston: Elsevier/Butterworth Heinemann.

Mejia, Maximo. 2002. "Defining Maritime Violence and Maritime Security". In Maritime Violence and Other Security Issues at Sea, edited by Proshanto K. Mukherjee, Maximo Mejia, and Gotthard M. Gauci. Malmo: WMU Publications. 
Mière, Christian Le. 2011. "Policing the waves: Maritime paramilitaries in the Asia-Pacific". Survival 53, no. 1: 133-146.

2014. Maritime Diplomacy in the 21st Century: Drivers and Challenges. 1. ed. Milton Park, Abingdon, Oxon: Routledge.

Morgan, Joseph R. 1994. "Constabulary Navies in the Pacific and Indian Oceans". Ocean Tearbook Online 11, no. 1: 368-83. https://doi. org/10.1163/221160094X00212.

Morris, Lyle J. 2017. "Blunt defenders of sovereignty: the rise of coast guards in East and Southeast Asia”. Naval War College Review 70, no. 2: 75-113.

. 2018. "China Welcomes Its Newest Armed Force: The Coast Guard". War on the Rocks, 4 de abril de 2018. https://warontherocks.com/2018/04/china-welcomes-its-newest-armed-force-the-coast-guard/.

Murphy, Martin N. 2007. "The Blue, Green, and Brown: Insurgency and Counterinsurgency on the Water”. Contemporary Security Policy 28, no. 1: 63-79. https:// doi.org/10.1080/13523260701240351.

. 2008. "Lifeline or Pipedream? Origins, Purposes, and Benefits of Automatic Identification System, Long-Range Identification and Tracking, and Maritime Domain Awareness". In Lloyd's MIU Handbook of Maritime Security, edited by Rupert Herbert-Burns, Sam Bateman, and Peter Lehr, 13-28. London: CRC press.

Ong, Graham, and Joshua Ho. 2005. Maritime Air Patrols: The New Weapon Against Piracy in the Malacca Straits. IDSS Commentaries. Singapura: S. Rajaratnam School of International Studies. https://www.rsis.edu.sg/rsis-publication/idss/731-maritime-air-patrols-the-new/\#.WpiUZGrwbIV.

Paleri, Prabhakaran. 2009. Coast guards of the world and emerging maritime threats. Tokyo: Ocean Policy Research Foundation.

Pozo, Fernando, Anthony Dymock, Lutz Feldt, Patrick Hebrard, and Ferdinando Monteforte. 2010. Maritime surveillance in support of CSDP. The Wise Pen Final Report to EDA Steering Board. Bruxelas: European Defense Agency. https:// www.eda.europa.eu/info-hub/press-centre/latest-news/2010/04/25/Wise_ Pen_Team_report_on_Maritime_Surveillance_MARSUR.

Rosenau, James. 1992. "Governance, Order, and Change in World Politics". In Governance without Government: Order and Change in World Politics, edited by James N. Rosenau, and Ernst-Otto Czempiel, 1-29. Cambridge: Cambridge University Press. 
Rubel, Robert C. 2012. "Command of the sea: an old concept resurfaces in a new form”. Naval War College Review 65, no. 4: 21.

Shearer, Ivan. 1998. "The Development of International Law with Respect to the Law Enforcement Roles of Navies and Coast Guards in Peacetime". International Law Studies 71, no. 1: 429-53.

Speller, Ian. 2014. Understanding Naval Warfare. New York: Routledge.

Sumida, Jon. 2001. "New insights from old books: The case of Alfred Thayer Mahan”. Naval War College Review 54, no. 3: 100-111.

Till, Geoffrey. 2009. Seapower: a guide for the twenty-first century. 2. ed. Abingdon: Routledge.

Routledge.

2012. Asia's Naval Expansion: An Arms Race in the Making? London: 2018. Seapower: A Guide for the Twenty-First Century. 4. ed. London; New York: Routledge.

United States. 1994. "Forward... From The Sea". Washington D.C. http://www. dtic.mil/dtic/tr/fulltext/u2/a338561.pdf.

. 2005. "National plan to achieve Maritime Domain Awareness". Washington D.C. https://www.dhs.gov/sites/default/files/publications/ HSPD_MDAPlan_o.pdf.

2007. "A cooperative strategy for the 21st Century". Washington D.C.

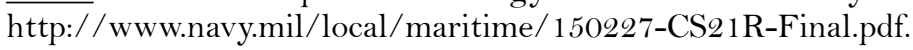

2010. "Department of Defense Dictionary of Military and Associated Terms”. https://fas.org/irp/doddir/dod/jp1_02.pdf.

Willett, Lee. 2018. "Strength on the Surface". Asian Military Review(May). https:// asianmilitaryreview.com/2018/05/strength-surface-frigates-destroyers/.

Wilson, Brian. 2016. “The Complex Nature of Today's Maritime Security: why whol-of-government frameworks matters". In Routledge Handbook of Naval Strategy and Security, edited by Sebastian Bruns, and Joachim Krause, 153-65. Cambridge; New York: Routledge. 


\section{RESUMO}

O objetivo do trabalho é estudar a relação dos fins e meios navais no âmbito da Zona Econômica Exclusiva. O argumento é de que a Governança da Segurança Marítima é um conceito melhor do que Comando do Mar para explicar o uso da força nessas áreas marítimas e que as forças navais precisam se reorganizar para atender às novas demandas de segurança.

Palavras-chave: Zona Econômica Exclusiva; Governança; Segurança Marítima; Guarda-Costeira.

\section{ABSTRACT}

The goal of the present paper is to study the relationship between the ends and naval means in the context of the Exclusive Economic Zone. The argument is that Maritime Security Governance is a better concept than Command of the Sea to explain the use of force in these maritime areas and that naval forces need to reorganize to meet the new security requirements.

Keywords: Exclusive Economic Zone; Governance; Maritime Security; Coast Guard. 